\title{
Teknik Pengujian Equivalents Partitioning pada Aplikasi Sistem Pendaftaran PAUD berbasis WEB dengan Menggunakan Black Box
}

\author{
Mauludin Yusup Suyudi ${ }^{1}$, Adinda Putriani Pratiwi ${ }^{2}$, Rachell Fauziah Mawahdah ${ }^{3}$, Yuda Andika \\ Purwara $^{4}$, Irpan Kusyadi ${ }^{5}$

\begin{abstract}
Teknik Informatika, Universitas Pamulang, Jl. Raya Puspitek No.46, Buaran, Serpong, Tangerang Selatan, Banten, Indonesia, 15310 4yudanapoleon@gmail.com, ${ }^{5}$ dosen00673@unpam.ac.id
\end{abstract} \\ e-mail : ${ }^{1}$ mauludin45@gmail.com, ${ }^{2}$ adindaputrianipratiwi@gmail.com, ${ }^{3}$ rachell.fauziah@gmail.com,
}

Submitted Date: June $03^{\text {rd }}, 2020$

Revised Date: June $30^{\text {th }}, 2020$
Reviewed Date: June $17^{\text {th }}, 2020$

Accepted Date: June $30^{\text {th }}, 2020$

\begin{abstract}
Testing is the most important thing to produce a system that is very good and also useful. Pengban a system must be carried out because if there is no prior testing of a system, then what will happen to the system will get a system error that results in a poor quality system and will result in a loss for developers and users. Experiments that have been carried out can find an error, disability, or failure on a system that has been known from the beginning and immediately corrected more thoroughly. In the test there are also types of system experiments, one of which is by testing the black box using an equivalent method that is good for looking for an error on the system. The equivalent method can break down the input domains of the program into a class that can solve test cases. Based on the results of a test that has been done, this application still has an error and also a defect in a system.
\end{abstract}

Keywords: Equivalent Method; Registration System; Black Box Testing

\section{Abstrak}

Pengujian merupakan hal terpenting untuk menghasilkan sebuah sistem yang sangat baik dan juga bermanfaat. Pengujan sebuah sistem harus dilaksanakan karena jika tidak adanya pengujian terlebih pada sebuah sistem, maka yang akan terjadi sistem tersebut akan mendapatkan sebuah kesalahan sistem yang mengakibatkan kualitas sebuah sistem yang buruk dan akan menagkibatkan sebuah kerugian bagi pengembang dan juga pemakai. Percobaan yang telah dilakukan dapat ditemukannya suatu kesalahan, kecacatan, ataupun kegagalan pada sebuah sistem yang telah diketahui dari awal dan segera diperbaiki dengan lebih teliti. Di pengujian tersebut juga ada jenis percobaan sistem, salah satunya adalah dengan pengujian kotak hitam dengan menggunakan sebuah metode setara yang bagus untuk mencari sebuah kesalahan pada sistem. Metode setara dapat memecah domain input dari program ke dalam sebuah kelas yang dapat memecahkan test case. Berdasarkan hasil dari sebuah pengujian yang telah dilakukan, aplikasi ini masih mempunyai sebuah kesalahan dan juga kecacatan pada sebuah sistemnya.

Kata kunci: Metode setara; Sistem Pendaftaran; Pengujian Kotak hitam

\section{Pendahuluan}

Pengujian sistem memiliki peranan yang penting untuk menjamin kualitas perangkat lunak yang dikembangkan. Pengujian sangat diperlukan dalam sistem informasi untuk memastikan aplikasi yang dikembangan telah memenuhi persyaratan teknis dan bisnis yang diharapkan sebelum diserahkan kepada pengguna (customer) (Febrian, Ramadhan,
Faisal, \& Saifudin, 2020). Pengujian sistem adalah suatu hal yang sangat perlu diperhatikan dan juga perlu diperhatikan, karena sangat dibutuhkan dengan tujuan untuk meyakinkan kualitas suatu sistem yang masih dalam tahap pengembangan ataupun yang sudah berjalan dengan baik tanpa adanya suatu kendala. Di pengujian sistem itu ada waktu tersendiri dalam mencari suatu kesalahan pada sistem, mencari 
kecacatan atau kekurangan pada sistem yang dapat diperbaiki saat itu juga.

Untuk dapat terciptanya kualitas suatu sistem yang baik, maka harus ada pengujian. Pengujian perangkat lunak bertujuan untuk mencari suatu kesalahan yang ada pada sistem tersebut. Maka dari itu software atau perangkat lunak yang akan digunakan harus diuji terlebih dulu. Pengujian perangkat lunak dapat menggunakan metode Black Box (Syuhada \& Nursikuwagus, 2018). Black Box Testing merupakan pengujian sebuah aplikasi yang terletak di luar perangkat lunak atau software yang di mana pada tampilan maupun inti dari suatu sistem yang diuji.

PAUD Nurul Muslihin ingin menggunakan perangkat lunak, di mana perangkat lunak tersebut diharapkan dapat membantu staff-staff PAUD tersebut mudah. Salah satunya adalah menggunakan aplikasi pendaftaran PAUD berbasis web. Pada pengujian perangkat lunak diperlukan memasukkan data untuk ke database yang mempunyai kemampuan terhadap pembacaan tipe - tipe data yang tidak tepat pada proses memasukkan data, sedangkan jika proses simpan data berjalan lancer maka akan muncul pesan data berhasil disimpan. Input data siswa PAUD merupakan komponen masukkan yang diuji.

Terkait dengan pengujian black-box, dalam pencarian kemungkinan data dan masukkan dalam mendesain test case dengan Teknik Equivalence bias menggunakan algoritma genetika. Dengan mempertimbangkan bahwa algoritma genetika pada pengujian GUI, maka akan dipilih algoritma genetika untuk optimasi dan otomatisasi desain test case pada saat pengujian perangkat lunak metode blackbox testing dengan Teknik Equivalence Partitions. Dalam proses pengujian perangkat lunak, di setiap kasus yang akan diuji wajib memiliki identitas dan mempunyai keterhubungan antara sekumpulan masukan dengan hasil yang diinginkan.

Equivalence Partitioning merupakan sebuah pengujian berdasarkan masukkan data pada setiap form yang memecah domain masukan ke dalam kelompok valid dan tidak valid (Aziz, Setiawan, Khanh, Nurdiyansyah, \& Yulianti, 2020). Teknik Equivalence Partitions merupakan sebuah pengujian berdasarkan masukan data pada setiap form yang ada pada sistem aplikasi informasi data kinerja, setiap menu masukan akan dilakukan pengujian dan dikelompokkan berdasarkan fungsinya baik itu bernilai valid ataupun tidak valid. Pengujian dilakukan pada 4 form yang akan diisi dengan data form tambah jobdesk, form tambah target kerja, form edit target kerja, form approve target kerja, serta kinerja karyawan selama di perusahaan.

\section{Metode Penelitian}

Pengujian software sangat penting dilakukan karena sering kali setiap orang membuat kesalahan pada saat pembuatan software dan kesalahan pada masing-masing akan berbeda. Tujuan dari pengujian adalah untuk memastikan bahwa sistem yang dihasilkan sesuai dengan kebutuhan dan layak untuk digunakan (Arwaz, Putra, Putra, Kusumawijaya, \& Saifudin, 2019).

Dalam melakukan pengujian harus memilih teknik yang tepat, yaitu teknik yang dapat menemukan kesalahan yang belum terdeteksi sehingga dapat meningkatkan kualitas software (Hendri, Manurung, Ferian, Hanaatmoko, \& Yulianti, 2020). Agar dapat menemukan kesalahan/cacat pada perangkat lunak harus digunakan teknik yang tepat. Pengujian yang dilakukan tidak lengkap dan efektif dapat menimbulkan masalah dan menyebabkan kerugian ketika software digunakan (Rosalina, Rassi, Hadi, Ubaidillah, \& Desyani, 2020). Sehingga sangat perlu untuk melakukan pengujian untuk mengurangi terjadinya kesalahan yang merugikan tersebut (Ningrum, Suherman, Aryanti, Prasetya, \& Saifudin, 2019).

Pengujian perangkat lunak dapat dilakukan antara lain:

- Pengujian Black Box

- Pengujian White Box

- Pengujian Equivalents Partition

\subsection{Pengujian Black box}

Metode ini dilakukan dengan cara mengeksekusi program yang diinginkan, kemudian program diamati hasilnya sudah sesuai dengan hasil yang diinginkan atau masih tidak sesuai. Pengujian ini akan diuji secara detail hingga menjadi program yang diinginkan. Jika masih terdapat kesalahan atau tidak sesuai dengan hasil yang diinginkan akan dicek satu per satu dan akan diperbaiki. Pengujian Black Box adalah rencana percobaan yang memperhatikan detail sistem serat aspek dari fingsinya, mengenali jenis-jenis kecacatan di 
jalan masuk ke dalam asal data disimpan (Cholifah, Yulianingsih, \& Sagita, 2018).

\subsection{Pengujian White Box}

Cara pengujiannya dengan melihat kedalam modul untuk meneliti kode program yang ada, dan menganalisa apa ada kesalahan atau tidak. Jika menghasilkan output yang tidak sesuai dengan proses yang dilakukan, maka variabel dan parameter yang ada pada unit akan dicek satu per satu dan diperbaiki hingga benar $100 \%$.

Pengujian white box:

a. mengetahui kerja suatu perangkat lunak secara internal.

b. Menjamin operasi internal dengan spesifikas yang ditetapkan mengganakan struktur dari prosedur yang dirancang.

\subsection{Pengujian Equivalents Partition}

Equivalence Partitions berdasarkan pada masukan dan keluaran dari suatu komponen yang dimasukkan ke dalam kelas-kelas (Hidayat \& Muttaqin, 2018). Spesifikasi komponen tersebut akan diperlakukan ekuivalen dengan komponen tersebut.

Teknik Equivalence Partitions merupakan sebuah pengujian berdasarkan masukan data pada setiap form yang ada pada sistem aplikasi informasi data kinerja, setiap menu masukan akan dilakukan pengujian dan dikelompokkan berdasarkan fungsinya baik itu bernilai valid ataupun tidak valid (MZ, 2016).

Pengujian dilakukan pada 4 form yang akan diisi dengan data form tambah jobdesk, form tambah target kerja, form edit target kerja, form approve target kerja, serta kinerja karyawan selama di perusahaan. Dengan menggunakan metode ini akan mendapatkan sebuah gambaran tentang kondisi penjaminan suatu kualitas perangkat lunak.

Pengujian dilakukan dengan pada form login pada Gambar 1 dan form pendaftaran pada Gambar 2 memakai pengujian kotak hitam dengan menggunakan metode setara. Pengujian dalam perangkat lunak, kasus akan diuji dan wajib memiliki mempunyai keterhubungan dan identitas dengan sekumpulan masukan dengan hasil yang diinginkan. Pengujian menunjukkan bahwa masih banyaknya masalah-masalah yang ada, sehingga perlu banyaknya perbaikanperbaikan yang harus dilakukan guna untuk perangkat lunak yang baik dan juga bermutu baik.

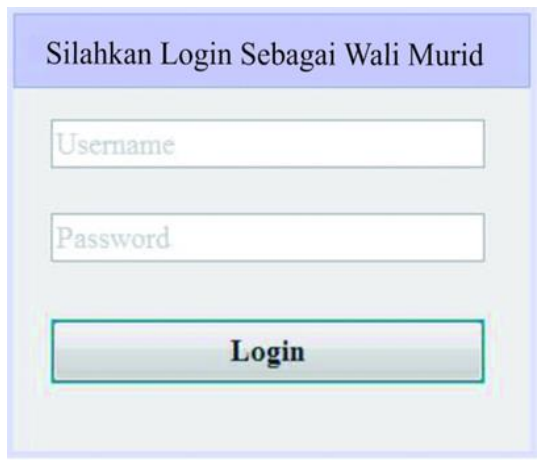

Gambar 1 Form Login

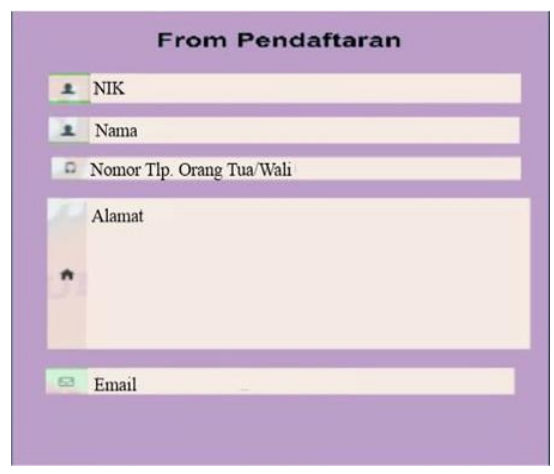

Gambar 2 Form Pendaftaran

Tabel 1 Input Data

\begin{tabular}{|l|l|}
\hline \multicolumn{1}{|c|}{ Input } & \multicolumn{1}{c|}{ Class } \\
\hline Nama & Huruf bisa menggunakan capital, huruf kecil, maupun angka \\
Nama : & \\
Adinda Yusup Fauziah Purwara & Char harus berisi 1-40 karakter \\
\hline Password & Kata sandi harus menggunakan angka maupun huruf \\
Masukkan : & \\
1234567890 & Varchar berisi 1-10 karakter \\
\hline
\end{tabular}




\section{Hasil dan pembahasan}

Untuk memulai pengujian pada kedua field tersebut, harus menyiapkan beberapa skenario untuk memulai pengujian, berikut ini merupakan tabel hasil ujinya.

Tabel 2 Tabel hasil uji

\begin{tabular}{|c|c|c|c|}
\hline Input & Class & $\begin{array}{l}\text { Pengujian } \\
\end{array}$ & Hasil uji \\
\hline $\begin{array}{l}\text { Nama } \\
\text { Nama : } \\
\text { Adinda Yusup } \\
\text { Fauziah Purwara }\end{array}$ & $\begin{array}{l}\text { Memasukkan huruf } \\
\text { A-Z atau a-Z } \\
1-40 \text { karakter (char) }\end{array}$ & $\begin{array}{l}\text { Input dapat diterima jika: } \\
\text { 1. Input nama lebih dari } 1 \text { karakter } \\
\text { 2. Menggunakan huruf besar atau } \\
\text { kecil }\end{array}$ & $\begin{array}{l}{[\sqrt{ }] \text { diterima }} \\
{[\text { ]ditolak }}\end{array}$ \\
\hline $\begin{array}{l}\text { Password } \\
\text { Masukan : } \\
\text { Anakuptit1 }\end{array}$ & $\begin{array}{l}1-10 \text { angka atau huruf } \\
\text { (varchar) }\end{array}$ & $\begin{array}{l}\text { Input password dapat diterima dengan } \\
\text { kombinasi angka dan huuf }\end{array}$ & $\begin{array}{l}{[\sqrt{ }] \text { diterima }} \\
{[\text { ]ditolak }}\end{array}$ \\
\hline
\end{tabular}

Ada 2 form yang diuji menggunakan Black Box, pengujian lebih dari 2 kali dengan total pengujian yaitu 8 kali pengujian, adanya kesalahan atau error pada pengujian sebanyak 24 kali. Pengujian form ini mempunyai 3 tabel yang di antaranya adalah solusi di mana berguna untuk memperbaiki sistem yang ada di perangkat lunak.

Pendaftaran siswa baru PAUD Nurul Muslihin yang dilakukan oleh wali murid tersebut. Form akan selalu terbuka dalam waktu yang telah ditentukan oleh admin PAUD Nurul Muslihin.

\section{Kesimpulan}

Data yang akurat dan informasi pendaftaran siswa yang lebih praktis dan tidak sulit. Dengan demikian, wali murid dari calon siswa PAUD Nurul Muslihin dengan mudah untuk mendaftarkan anak-anaknya untuk sekolah tanpa harus mendatangi sekolah tersebut.

Setelah dilakukan pembahasan dan pengujian terhadap sistem pendaftaran siswa, maka beberapa kesimpulan sebagai berikut:

1. Membantu admin untuk menyusun data dengan sistem yang telah dibuat tanpa manual kembali

2. Mempermudah seseorang pengembang sistem untuk mengembangkan kesalahan yang telah ditemukan pada pengujian.

3. Pada sistem informasi ini digunakan metode Black Box dengan metode equivalent partition tipe pengujian dengan hasil yang baik, sehingga beberapa kesalahan atau kelemahan dalam sistem informasi dapat ditemukan.
4. 4.Memudahkan wali murid untuk mendaftarkan anaknya di PAUD Nurul Muslihin tanpa harus datang ke sekolah

5. Memanfaatkan teknologi untuk tidak menggunakan kertas, dan dapat menjaga bumi dari kerusakan alam.

\section{Saran}

Dari hasil di atas, bisa disimpulkan bahwa ada beberapa saran yang harus dikerjakan, sebagai salah satu alternatif pemikiran untuk harapan yang lebih baik bagi PAUD Nurul Muslihin. Agar lebih mudah dan lebih baik, perangkat lunak berbasis web yang sudah diuji dengan kotak hitam dan metode setara bisa digunakan dengan staf-staf yang ada di PAUD Nurul Muslihin.

\section{Referensi}

Arwaz, A. A., Putra, K., Putra, R., Kusumawijaya, T., \& Saifudin, A. (2019). Pengujian Black Box pada Aplikasi Sistem Seleksi Pemenang Tender Menggunakan Teknik Equivalence Partitions. Jurnal Teknologi Sistem Informasi dan Aplikasi, $\quad$ 2(4), $\quad 130-134$. doi:10.32493/jtsi.v2i4.3708

Aziz, I. A., Setiawan, B., Khanh, R., Nurdiyansyah, G., \& Yulianti, Y. (2020). Pengujian Black Box pada Aplikasi Sistem Kasir Berbasis Website Menggunakan Teknik Equivalence Partitions. Jurnal Teknologi Sistem Informasi dan Aplikasi, 3(2), 10.32493/jtsi.v3i2.4693. doi:10.32493/jtsi.v3i2.4693 
Cholifah, W. N., Yulianingsih, \& Sagita, S. M. (2018, December). Pengujian Black Box Testing Pada Aplikasi Action \& Strategy Berbasis Android Dengan Teknologi Phonegap. Jurnal String Vol 3 No 2, 1-5.

Febrian, V., Ramadhan, M. R., Faisal, M., \& Saifudin, A. (2020). Pengujian pada Aplikasi Penggajian Pegawai dengan menggunakan Metode Blackbox. Jurnal Informatika Universitas Pamulang, 5(1), 61-66. doi:10.32493/informatika.v5i1.4340

Hendri, H., Manurung, J. W., Ferian, R. A., Hanaatmoko, W. F., \& Yulianti, Y. (2020). Pengujian Black Box pada Aplikasi Sistem Informasi Pengelolaan Masjid Menggunakan Teknik Equivalence Partitions. Jurnal Teknologi Sistem Informasi dan Aplikasi, $\quad 3(2), \quad$ 107-113. doi:10.32493/jtsi.v3i2.4694

Hidayat, T., \& Muttaqin, M. (2018, April). Pengujian Sistem Informasi Pendaftaran dan Pembayaran Wisuda Online menggunakan Black Box Testing dengan Metode Equivalence Partitioning dan Boundary Value Analysis. Jurnal Teknik Informatika UNIS, 1-5.

MZ, M. K. (2016). Pengujian Perangkat Lunak Metode Black-Box Berbasis Equivalence Partitions Pada Aplikasi Sistem Informasi Sekolah. Jurnal Mikrotik, 2-8.

Ningrum, F. C., Suherman, D., Aryanti, S., Prasetya, H. A., \& Saifudin, A. (2019, December). Pengujian Black Box pada Aplikasi Sistem Seleksi Sales Terbaik Menggunakan Teknik Equivalence Partitions. Jurnal Informatika Universitas Pamulang, 1-6.

Rosalina, A., Rassi, A. A., Hadi, G. Y., Ubaidillah, R., \& Desyani, T. (2020). Pengujian Black Box pada Sistem Informasi Penjualan HI Shoe Store Menggunakan Teknik Equivalence Partitions. Jurnal Informatika Universitas Pamulang, 5, 26-29. doi:10.32493/informatika.v5i1.3964

Syuhada, D. A., \& Nursikuwagus, A. (2018). Pengujian Aplikasi Perhitungan Stok Barang Dengan Metode Blackbox Pada CV. Delta Pilar. Jurnal Universitas Komputer Indonesia, 1-7. 